\title{
Protein-Binding Function of RNA-Dependent Protein Kinase Promotes Proliferation through TRAF2/RIP1/NF-kB/c-Myc Pathway in Pancreatic $\beta$ cells
}

\author{
LiLi Gao, ${ }_{1,2^{*}}$ Wei Tang, ${ }^{3 *}$ ZhengZheng Ding, ${ }^{1,2}$ DingYu Wang, ${ }^{1,2}$ XiaoQiang Qi, ${ }^{1,2}$ HuiWen Wu, ${ }^{4}$ and \\ Jun Guo ${ }^{1,2}$
}

${ }^{1}$ Key Laboratory of Human Functional Genomics of Jiangsu Province, and ${ }^{2}$ Department of Biochemistry and Molecular Biology, Nanjing Medical University, Nanjing, People's Republic of China; ${ }^{3}$ Department of Endocrinology, The Affiliated Jiangyin Hospital of Southeast University Medical College, Jiangyin, People's Republic of China; and ${ }^{4}$ Laboratory Center for Basic Medical Sciences, Nanjing Medical University, Nanjing, People's Republic of China

\begin{abstract}
Double-stranded RNA-dependent protein kinase (PKR), an intracellular pathogen recognition receptor, is involved both in insulin resistance in peripheral tissues and in downregulation of pancreatic $\beta$-cell function in a kinase-dependent manner, indicating PKR as a core component in the progression of type 2 diabetes. PKR also acts as an adaptor protein via its protein-binding domain. Here, the PKR protein-binding function promoted $\beta$-cell proliferation without its kinase activity, which is associated with enhanced physical interaction with tumor necrosis factor receptor-associated factor 2 (TRAF2) and TRAF6. In addition, the transcription of the nuclear factor kappa-light-chain-enhancer of activated B cell (NF-kB)-dependent survival gene c-Myc was upregulated significantly and is necessary for proliferation. Upregulation of the PKR protein-binding function induced the NF- $\mathrm{B}$ pathway, as observed by dose-dependent degradation of $I_{\kappa} B \alpha$, induced nuclear translocation of p65 and elevated NF- $\kappa B-d e-$ pendent reporter gene expression. NF-кB-dependent reporter activity and $\beta$-cell proliferation both were suppressed by TRAF2siRNA, but not by TRAF6-siRNA. TRAF2-siRNA blocked the ubiquitination of receptor-interacting serine/threonine-protein kinase 1 (RIPI) induced by PKR protein binding. Furthermore, RIPI-siRNA inhibited $\beta$-cell proliferation. Proinflammatory cytokines (TNF $\alpha$ ) and glucolipitoxicity also promoted the physical interaction of PKR with TRAF2. Collectively, these data indicate a pivotal role for PKR's protein-binding function on the proliferation of pancreatic $\beta$ cells through TRAF2/RIP1/NF-KB/c-Myc pathways. Therapeutic opportunities for type 2 diabetes may arise when its kinase catalytic function, but not its protein-binding function, is downregulated.
\end{abstract}

Online address: http://www.molmed.org

doi: 10.2119/molmed.2014.00235

\section{INTRODUCTION}

Double-stranded RNA-dependent protein kinase (PKR) is well known as a pathogen recognition receptor against virus infection and a tumor suppressor in cell growth (1-6). During virus infection, PKR is activated and blocks viral protein synthesis through phosphorylation of eIF2 $\alpha$, thus leading to antiviral defense $(1,3,7)$. Recently, it was observed that PKR is involved in insulin resistance in peripheral tissues (8-11) and antiproliferation activities in pancreatic $\beta$ cells (12), indicating a novel role of PKR in

${ }^{*} G L$ and TW contributed equally to this paper.

Address correspondence to Jun Guo, Key Laboratory of Human Functional Genomics of Jiangsu Province, Department of Biochemistry and Molecular Biology, Nanjing Medical University, Nanjing 210029, PR China. Phone: +86-(0)25-86862729; Fax: +86-(0)25-86862728; E-mail:guoj@njmu.edu.cn; guoj69@aliyun.com.

Submitted November 23, 2014; Accepted for publication February 18, 2015; Published Online (wWw.molmed.org) February 18, 2015.

The Feinstein Institute for Medical Research

North Empowering Imagination. Pioneering Discovery.

metabolism regulation and type 2 diabetes mellitus (T2DM). These functions of PKR are attributed to its kinase catalytic activity and an effective therapeutic strategy of pharmacologically targeting PKR was confirmed using small-molecule inhibitors of PKR kinase activity that improved insulin sensitivity and glucose clearance in a mouse model of obesity and insulin resistance (13).

Notably, PKR can function as an adaptor protein via its protein-binding domain, but not via its regulatory dsRNA-binding domain $(14,15)$. Structurally, there are two tumor necrosis factor receptor-associated factor (TRAF)-binding domains with one TRAF-interacting motif $\mathrm{P} / \mathrm{S} / \mathrm{A} / \mathrm{T} \times$ $\mathrm{Q} / \mathrm{E} \mathrm{E}$ in the regulatory domain and another, $\mathrm{P} \times \mathrm{Q} \times \mathrm{S} / \mathrm{T} / \mathrm{D}$, in the kinase do- 
main (14). In unstimulated cells, the two motifs are embedded in the closed conformation of PKR that is mediated by inhibitory intramolecular interactions $(16,17)$. Upon ligand binding, dimerization of PKR is induced and conformation occurs to expose the TRAF-binding domains. TRAF family members, including TRAF2, TRAF5 and TRAF6, combine with PKR upon dimerization in some cells (14). Despite the existence of TRAF-interacting motifs on PKR, physical interaction between PKR and TRAF proteins in pancreatic $\beta$ cells remains elusive.

TRAF family members originally were identified as signaling adaptors, with a TRAF domain at the C-terminus to interact with upstream recruiter molecules (such as TLR, TNFR, CD40, PKR and a really interesting new gene [RING] finger and several zinc finger motifs in the $\mathrm{N}$-terminal domain) to combine with and activate downstream molecules, including receptor-interacting serine/threonineprotein kinase 1 (RIP1) and other TRAF family members $(14,15)$. TRAF family members play a critical role in signaling transduction forward to the nuclear factor kappa-light-chain-enhancer of acti-

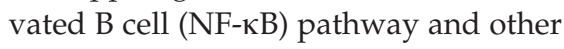
transcriptional modulations (18-20). For example, TNF $\alpha$ mediates constitutive NF- $\kappa \mathrm{B}$ activation and proliferation in human head and neck squamous cell carcinoma through the TRAF signaling pathway (21).

The aims of this investigation were to determine the effect of the proteinbinding domain of PKR on pancreatic $\beta$ cells and to analyze the underlying mechanism. Under the conditions where the kinase catalytic activity was defective, the protein-binding function of PKR was shown to promote $\beta$-cell proliferation, suggesting a role of the PKR protein-binding domain distinct from its kinase activity. If small pharmacological molecules could agonize the proteinbinding function to counteract the kinase activity of PKR in vivo, then therapeutic opportunities in T2DM may arise.

\section{MATERIALS AND METHODS}

\section{Reagents}

Roswell Park Memorial Institute (RPMI) 1640, Dulbecco modified Eagle medium and fetal bovine serum (FBS) were Gibco products (Thermo Fisher Scientific Inc., Waltham, MA, USA). TRIzol and Lipofectamine 2000 reagent were Invitrogen products (Thermo Fisher Scientific). The Reverse Transcription Kit and the SYBR Green PCR Master Mix were bought from Takara (Otsu, Shiga, Japan). Type V collagenase, Histopaque-1077, MTT and coumermycin were obtained from Sigma-Aldrich (St. Louis, MO, USA). TNF $\alpha$ was purchased from PeproTech (Rocky Hill, NJ, USA). The CellLightEdU DNA Cell Proliferation Kit was purchased from RiboBio (Guangzhou, China). TRAF2-siRNA, TRAF6-siRNA, RIP1-siRNA, $c-M y c$-siRNA and antibodies against $\beta$-actin, PKR, eIF2 $\alpha$, p-eIF $2 \alpha$, TRAF2, TRAF6, RIP1 and ubiquitin were obtained from Santa Cruz Biotechnology (Santa Cruz, CA, USA). Antibodies against Cyclin D1, Cyclin D2, Cdk2, Cdk4 and c-Myc were from Cell Signaling Technology (Boston, MA, USA). Antibodies against P21, P27 and P53 were purchased from Bioss (Beijing, China). The NF-кB-dependent reporter construct pGMNFкB-Lu was purchased from Genomeditech (Shanghai, China). Bay117082, ortho-Nitrophenyl- $\beta$-galactoside, RIPA lysis buffer, nuclear and cytoplasmic protein extraction kit and BCA kit were obtained from Beyotime Inc (Shanghai, China). Plasmids encoding PKRK296R, GyrB-PKR, GyrB-PKR-K296H and pSG5 (22) were provided by Tom Dever (National Institutes of Health, Bethesda, MD, USA).

\section{Cell Culture and Transfection}

The MIN6 cell line was grown in Dulbecco modified Eagle medium (4.5 g/L glucose) containing 15\% (v/v) FBS, $121 \mathrm{~mol} / \mathrm{L}$ 2-mercaptoethanol (23). Lipofectamine 2000 (Invitrogen [Thermo Fisher Scientific]) was used for transfection of siRNAs and plasmid constructs, according to the manufacturer's instructions.

\section{Islet Isolation, Culture and In Vitro Transfection}

All animal studies were performed according to guidelines established by the Research Animal Care Committee of Nanjing Medical University (Nanjing, China). Ten-week-old (20-25 g) male imprinting control region (ICR) mice were purchased from the Model Animal Research Center of Nanjing University. All animals were handled in accordance with the Guide for the Care and Use of Laboratory Animals (24). Islet isolation and culturing techniques have been described previously (25).

At 2-d postisolation, the isolated islets were transferred to and cultured in serum-free transfection medium $\left(\mathrm{Ca}^{2+}\right.$ containing Krebs-Ringer-HEPES medium) and in vitro transfection was conducted as described previously (26).

\section{Protein Isolation and Western Blotting}

The protein concentrations were determined using a BCA kit (Beyotime Inc., China). Denatured samples were prepared for Western blot analysis using various primary antibodies as indicated. Protein signals were detected using secondary antibodies against rabbit or mouse IgG.

\section{Coimmunoprecipitation}

The same amounts (400 $\mu \mathrm{g})$ of cell lysates were incubated with 1 to $2 \mu \mathrm{g}$ antibody overnight at $4^{\circ} \mathrm{C}$. Protein A/Gagarose spheres (Santa Cruz Biotechnology) were added to the samples and stored at $4^{\circ} \mathrm{C}$. After $2 \mathrm{~h}$, the samples were centrifuged at $14,000 \mathrm{~g}$ for $2 \mathrm{~min}$ at $4^{\circ} \mathrm{C}$. The samples were then washed three times with lysis buffer and $20 \mu \mathrm{L}$ $5 \times$ SDS loading buffer was added before boiling for $10 \mathrm{~min}$. Denatured samples were kept at $-20^{\circ} \mathrm{C}$ for Western blotting (27).

\section{Quantitative Real-Time Reverse Transcription-Polymerase Chain Reaction (qRT-PCR) Analysis}

Total RNA was isolated using the TRIzol reagent. By using a reverse transcription kit, $1 \mu \mathrm{g}$ of total RNA was con- 
verted into first-strand cDNA. SYBR Green and the 7300 Real-Time PCR system (Applied Biosystems [Thermo Fisher Scientific]) were used to carry out the qRT-PCR analysis. All data were analyzed using $\beta$-actin gene expression as an internal standard.

\section{Cell Viability}

For MTT measurement, MIN6 cells were seeded in 96-well plates at a density of $1 \times 10^{4}$ cells/well and then subjected to the indicated treatments.

Thereafter, $20 \mu \mathrm{L}$ of $5 \mathrm{mg} / \mathrm{mL}$ MTT was added to each well and incubated for

$4 \mathrm{~h}$. The supernatant was removed and the formazan crystals were dissolved in dimethyl sulfoxide. Cell viability was assessed by measuring the absorbance at $490 \mathrm{~nm}$ using a microplate reader (12).

\section{Cell Proliferation Assay by 5-Ethynyl-2'-Deoxyuridine EdU Labeling}

For the EdU incorporation assay, MIN6 cells were cultured in 24-well plates on coverslips. After treatment, EdU was added to the culture medium (50 $\mu \mathrm{mol} / \mathrm{L})$ for $2 \mathrm{~h}$ and cell proliferation was determined according the manufacturer's instructions. For the isolated mouse islets, media supplemented with $20 \mu \mathrm{mol} / \mathrm{L}$ EdU was added to the plates. Isolated mouse islets are not adherent and could not easily be made adherent, therefore, an alternative protocol for suspended cells was used and centrifugation $\left(5 \mathrm{~min}, 4^{\circ} \mathrm{C}, 268 \times g\right)$ was required for every step.

\section{Immunofluorescence Assay (IFA)}

IFA was used to observe changes in the localization of NF- $\kappa B$ (p65) or the level of PKR, as described previously (12). After transfection and pharmaceutical treatment, MIN6 cells or isolated mouse islets were subjected to IFA. Antibodies against insulin were applied to mark pancreatic $\beta$ cells of islets. Isolated mouse islets in suspension were subject to centrifugation $\left(5 \mathrm{~min}, 4^{\circ} \mathrm{C}, 268 \times g\right.$ ) for every step (23).

\section{Flow Cytometric Analysis}

MIN6 cells were digested in a trypsinEDTA solution, collected by centrifugation at $500 \mathrm{~g}$ for $5 \mathrm{~min}$, washed three times with PBS and at last fixed in cold 75\% ethanol at $4^{\circ} \mathrm{C}$ overnight. The percentages of cells in G0/G1, S and G2/M phases were determined by flow cytometry following propidium iodide (PI) staining.

\section{Luciferase Reporter Assay}

The luciferase reporter construct pGMNF-кB-Lu was cotransfected transiently with pSG5 or GyrB-PKR-K296H into MIN6 cells grown in 24-well plates, using the lipofectamine 2000 reagent according to the manufacturer's instructions. A plasmid expressing the geneencoding $\beta$-galactosidase driven by the cytomegalovirus (CMV) promoter (Clontech Laboratories, Palo Alto, CA, USA) was cotransfected simultaneously as an internal control. The medium was replaced $6 \mathrm{~h}$ after transfection. Twentyfour hours after transfection, the cells were treated with the specific ligand coumermycin for an additional $24 \mathrm{~h}$ and harvested for luciferase reporter assays, as described previously (28). Similar protocol for PKR-K296R-induced MIN6 cells was conducted.

\section{Statistics}

All data were representative of at least three experiments. Results are expressed as the mean \pm SEM. Comparisons were performed using the Student $t$ test for two groups or analysis of variance (ANOVA) for multiple groups. $P$ values $<0.05$ were considered statistically significant.

All supplementary materials are available online at www.molmed.org.

\section{RESULTS}

\section{A Model of PKR with Its Protein-Binding Function but without Its Kinase Catalytic Activity Was Built into Pancreatic $\beta$ cells}

To explore the function of the PKR protein-binding domain in pancreatic $\beta$ cells, a plasmid encoding a GyrB-PKR$\mathrm{K} 296 \mathrm{H}$ fusion protein was used to overexpress a kinase-defective mutant in pancreatic $\beta$ cells. This fusion protein comprises the N-terminal 220 aa of Escherichia coli GyrB and the kinase domain (aa 258 to 551) of PKR with a mutation at position 296 from $\mathrm{K}$ to $\mathrm{H}$. The presence of E. Coli GyrB permits the chimeric protein to dimerize and conformationally change when treated with the specific inducer, coumermycin (22). To examine whether coumermycin would interfere with the potential activation of endogenous PKR, both the PKR inhibitor 2-AP and the agonist $\operatorname{BEPP}(12,29,30)$ were applied as a negative and positive control, respectively. As shown in Figure 1A, the protein levels of p-eIF2 $\alpha$ did not change upon coumermycin stimulus among the four transfected groups. On the other hand, the levels in coumermycin groups were obviously lower than those in the BEPP group $(P<0.01)$, despite no significant difference with mock or 2-AP groups. This observation implied that coumermycin could not trigger endogenous PKR kinase activity. A significant increase in the amount of PKR protein (about 3.5 times more than that in endogenous PKR, Figure 1C) was detected by Western blotting after GyrB-PKR$\mathrm{K} 296 \mathrm{H}$ overexpression. To examine the feasibility of PKR combining with TRAF proteins, qRT-PCR was carried out to detect the mRNA levels of TRAF2, TRAF3, TRAF5 and TRAF6 in MIN6 cells. Interestingly, except for TRAF5, the other three TRAF members were detected in pancreatic $\beta$ cells, and the mRNA level of TRAF3 was the highest (Figure 1B). Western blotting was then performed to detect TRAF2, TRAF3 and TRAF6 after immunoprecipitation of PKR with PKRspecific antibodies. Under conditions of PKR overexpression, coumermycin induced coimmunoprecipitation of PKR with TRAF2 and TRAF6, while TRAF3 was not detected as a negative control (see Figure 1C). Additionally, IFA with anti-PKR antibodies (red fluorescence) was carried out to detect the alterations 
A
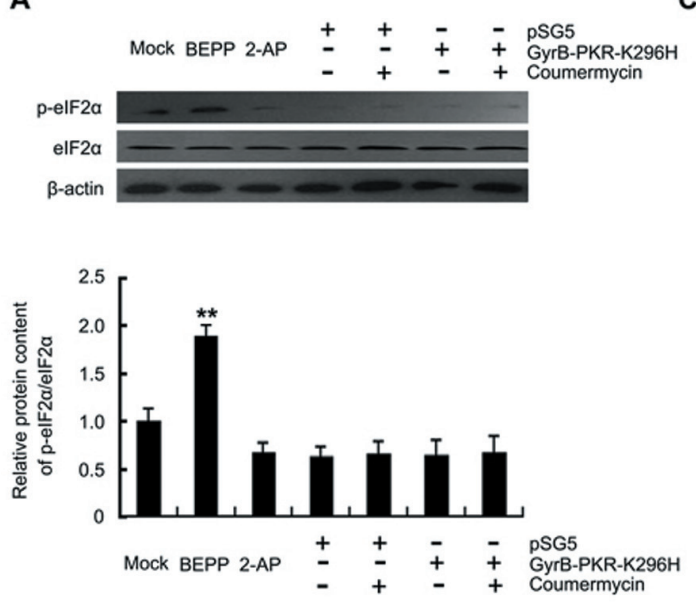

B

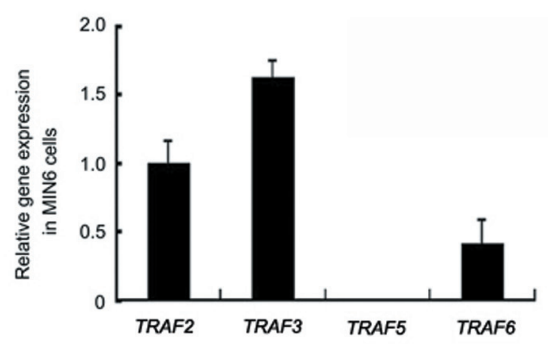

C

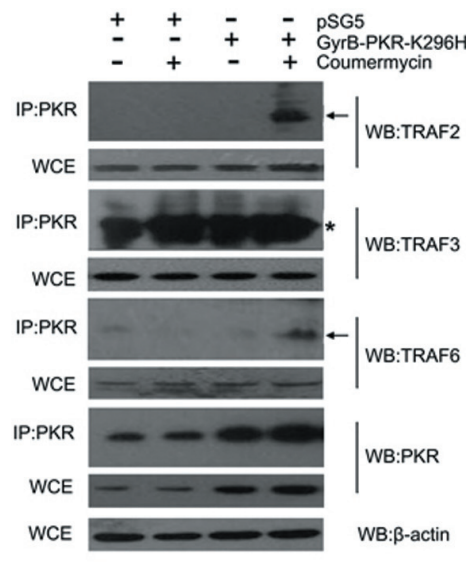

coumermycin could effectively enhance the viability of MIN6 in a dose- and time-dependent manner in the groups transfected with plasmid GyrB-PKR$\mathrm{K} 296 \mathrm{H}$, whereas there were no obvious changes among the groups transfected with vector pSG5 (Figure 2A). Moreover, cell viability reached its peak when MIN6 cells were treated with $10 \mathrm{ng} / \mathrm{mL}$ coumermycin for $24 \mathrm{~h}$ after transfection with plasmid GyrB-PKR$\mathrm{K} 296 \mathrm{H}$. The condition of $10 \mathrm{ng} / \mathrm{mL}$ coumermycin for $24 \mathrm{~h}$ was used in the experiments where coumermycin would be applied. Accordingly, we then investigated whether PKR protein-bindingmediated enhancement in $\beta$-cell viability was derived from increased proliferation. After coumermycin treatment, the percentage of EdU-positive $\beta$ cells in GyrB-PKR-K296H-induced MIN6 cells was elevated as compared to the other groups (Figure 2B). Meanwhile, flow cytometry showed a decreased percentage of MIN6 cells in the G1 phase (Figure $2 C, P<0.05)$ and an increased percentage in the $S$ phase (Figure $2 \mathrm{D}, P<0.05$ ) in the group with elevated PKR proteinbinding function. By contrast, coumermycin-dependent dimerization of GyrB-PKR had a similar biological function to activated PKR in MIN6 cells. That is, it could induce persistent phosphorylation of eIF2 $\alpha$ and inhibit cell proliferation through cycle arrest at G1 phase (Supplementary data). Similar EdU staining results were observed in primary islets (Figure 2E, $P<0.05$ ), indicating that PKR protein binding could effectively increase the proliferation of $\beta$ cells. The data suggested that the PKR protein-binding function improves both cell viability and proliferation in pancreatic $\beta$ cells, separate from its kinase function.

\section{Protein-Binding Function of PKR Upregulated Transcription of $C-M y c$ in MIN6 Cells}

Many molecules that govern cell cycle progression from the G1 to $S$ phase play a pivotal role in pancreatic $\beta$-cell proliferation $(12,23,31-35)$. In the $\beta$ cells.
$100 \mathrm{ng} / \mathrm{mL}$ ) for different time periods $(6 \mathrm{~h}, 12 \mathrm{~h}$ and $24 \mathrm{~h}$ ) after transfection in MIN6 cells. MTT assays indicated that

\section{Protein-Binding Function of PKR Proliferation of Pancreatic $\beta$ cells}

To evaluate the functional impact of the PKR protein-binding domain in pancreatic $\beta$-cells' growth, coumermycin was used in the experiment at different concentrations $(0,0.1,1,10$ and PKR protein-binding function, but defective in kinase catalytic activity, has been constructed successfully in pancreatic

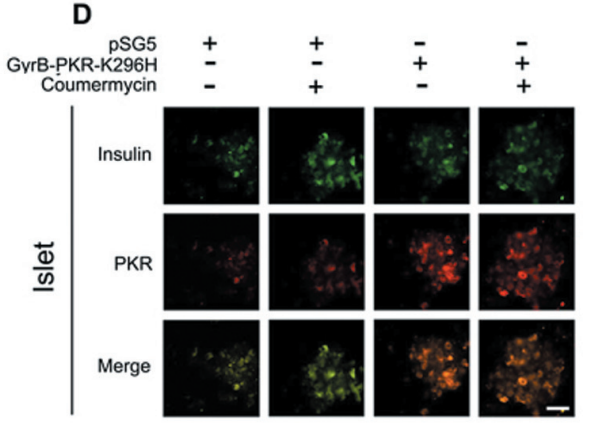


A
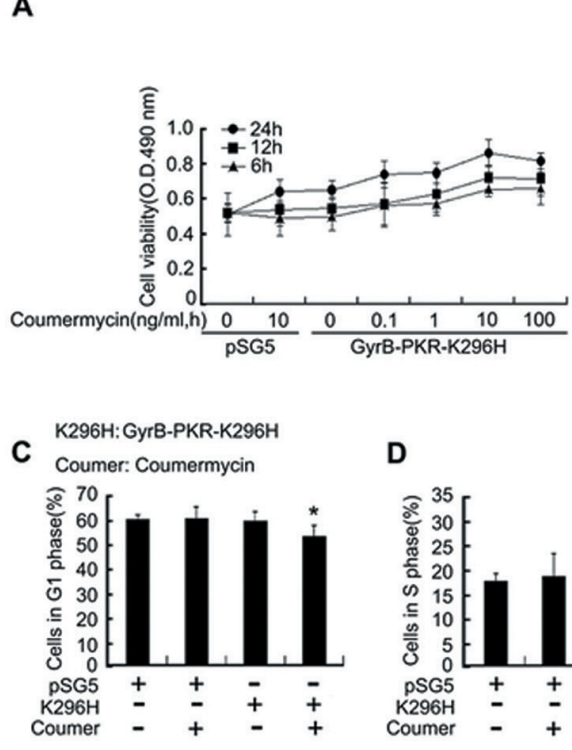

D
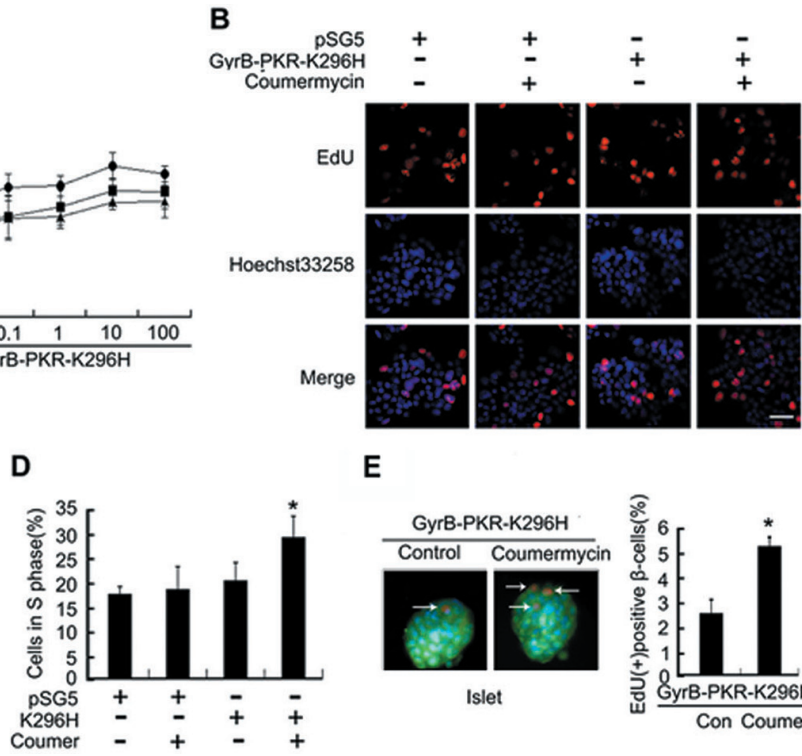

E

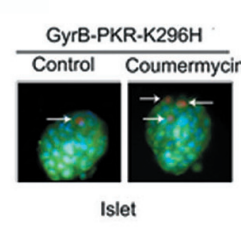

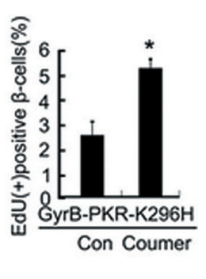

Figure 2. The PKR protein-binding function improves both cell viability and proliferation in pancreatic $\beta$ cells. Twenty-four hours after transfection, MIN6 cells were treated with the indicated concentrations of coumermycin for the indicated times. (A) Cell viability was assessed by the MTT assay. (B) DNA synthesis was analyzed using EdU labeling assays. Representative micrographs of EdU labeling assays in MIN6 cells are shown (scale bar $=120 \mu \mathrm{m}$ ). Flow cytometric assays were performed with percentages of MIN6 cells at the (C) G1 phase and (D) S phase. (E) Isolated mouse islets were administered as MIN6 cells and DNA synthesis was analyzed using EdU labeling assays. In primary islets, insulin with green staining was used to mark $\beta$ cells (scale bar $=100 \mu \mathrm{m}$ ), and the percentage of EdU-positive $\beta$ cells was quantificated (using six islets for each group). Arrows indicate the EdU-positive $\beta$ cell. Data are means \pm SEM of three separate experiments. ${ }^{*} P<0.05$ versus control.

present study, positive regulators such as cyclin D1, cyclin D2, CDK2, CDK4 and $c-M y c$, and negative regulators such as $p 21, p 27$ and $p 53$, were analyzed by qRT-PCR and Western blotting. After MIN6 cells were transfected with plasmid GyrB-PKR-K296H and treated with coumermycin (10 ng/mL, $24 \mathrm{~h}$ ), only the RNA level of $c-M y c$ was increased significantly compared with the control group without coumermycin treatment (Figure 3A, $P<0.01$ ), implying a transcriptional upregulation of $c-M y c$ upon PKR binding. Consistently, Western blotting showed a significant increase of $\mathrm{c}-\mathrm{Myc}$ protein in the same group (Figure $3 \mathrm{~B}, P<0.01$ ), whereas there were no remarkable changes for the other regulators (Figures 3B, C). To get deep insight into the role of c-Myc in the PKR protein-binding function-mediated $\beta$-cell proliferation, si-c-Myc was used to get gene silence of $c-M y c$. By comparison with the si-NC group, si-c-Myc was shown to greatly inhibit MIN6 cell proliferation (Figure 3D, $P<0.05$ ), and disturb cycle progression by increasing the percentage of cells at G1 phase (Figure $3 \mathrm{E}, P<0.05)$ and decreasing the percentage at $S$ phase (see Figure 3E, $P<0.05)$. Taken together, these data suggested that the PKR protein-binding function could upregulate the c-Myc protein level by increasing its transcription in MIN6 cells and c-Myc was essential for this proliferative effect.

\section{NF-кB Is Required for PKR Protein-Binding Domain-Induced c-Myc Upregulation and Cell Proliferation in MIN6 Cells}

c-Myc is thought to be modulated by NF-кB-dependent transcriptional activ- ity $(33,36-38)$. Therefore, we explored the possible involvement of the NF- $\kappa B$ pathway in PKR binding-triggered signals in pancreatic $\beta$ cells. After transfection of GyrB-PKR-K296H, MIN6 cells were pretreated with the NF- $\mathrm{BB}$-specific inhibitor Bay11-7082 $(39,40)(30 \mu \mathrm{mol} / \mathrm{L})$ $2 \mathrm{~h}$ before coumermycin administration. Compared with the control group, Bay11-7082 remarkably abolished the increase of $c-M y c$ mRNA level (Figure 4A, $P<0.01)$ and induced a significant decline of the c-Myc protein level (Figure $4 \mathrm{~B}$, down to $50 \%$ ). Based on the negative effect of Bay11-7082, NF-кB was implicated in the PKR proteinbinding-induced c-Myc upregulation. Meanwhile, the percentage of EdUpositive $\beta$ cells in MIN6 cells (Figure 4C, $P<0.01$ ) and primary islets (Figure 4F, $P<0.01)$ decreased substantially upon Bay11-7082 stimulus. Consistently, Bay11-7082 was shown to increase the percentage of MIN6 cells in G1 phases (Figure $4 \mathrm{D}, P<0.05$ ) and to decrease the percentage in the $S$ phase (Figure $4 \mathrm{E}$, $P<0.05)$. Taken together, these data support the requirement of NF- $\mathrm{KB}$ in the PKR protein-binding domain-induced MIN6 cell proliferation through transcriptional upregulation of the $c-M y c$ gene.

\section{NF-kB Was Activated by PKR Protein Binding in MIN6 Cells}

We next sought to explore whether PKR protein binding would activate NF- $\kappa$ B. The translocation of $\mathrm{p} 65 \alpha$ from the cytoplasm to the nucleus, preceded by proteolytic degradation of $I \kappa B$, is a necessary step for NF-кB transcriptional activity (41,42). As shown in Figure 5A, coumermycin substantially induced IкB $\alpha$ degradation $(P<0.01)$ and nuclear translocation of p65 $(P<0.01)$ in a dosedependent manner in GyrB-PKRK296H-induced MIN6 cells. Correspondingly, obvious translocation of p65 into the nucleus in MIN6 cells was observed in the group with elevated protein-binding function of PKR, using IFA with an anti-p65 antibody (green fluorescence, Figure 5B). Demonstration of 
A

B
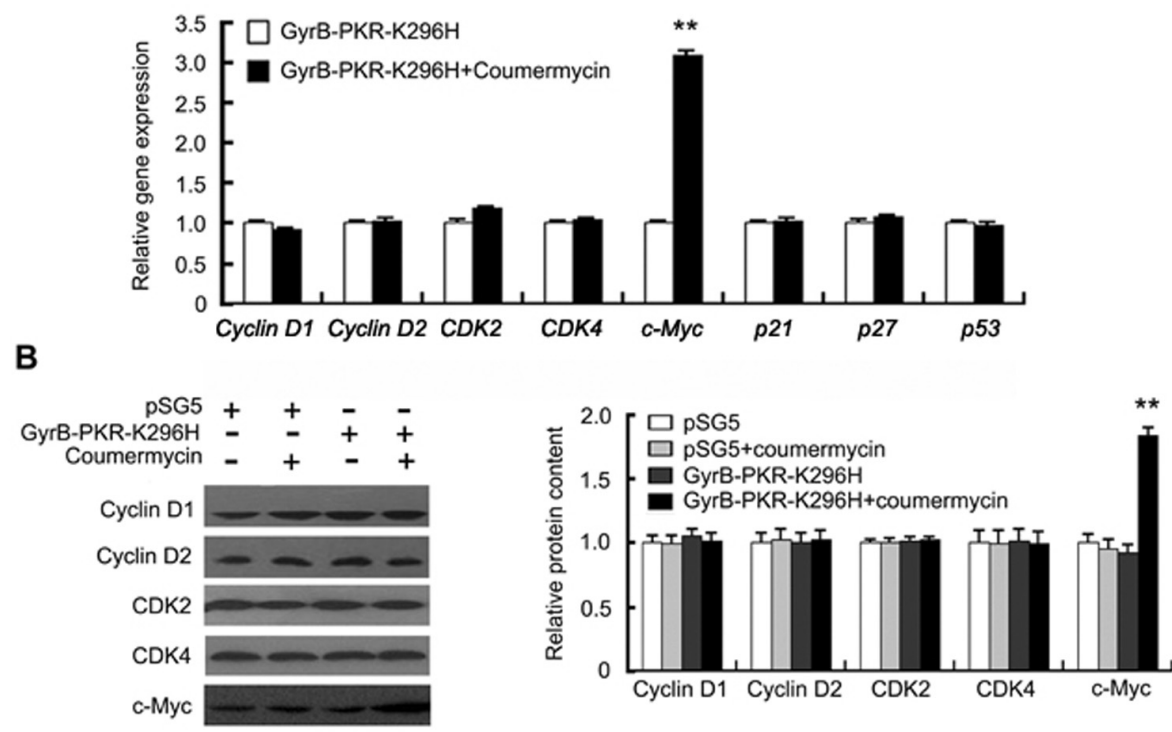

C
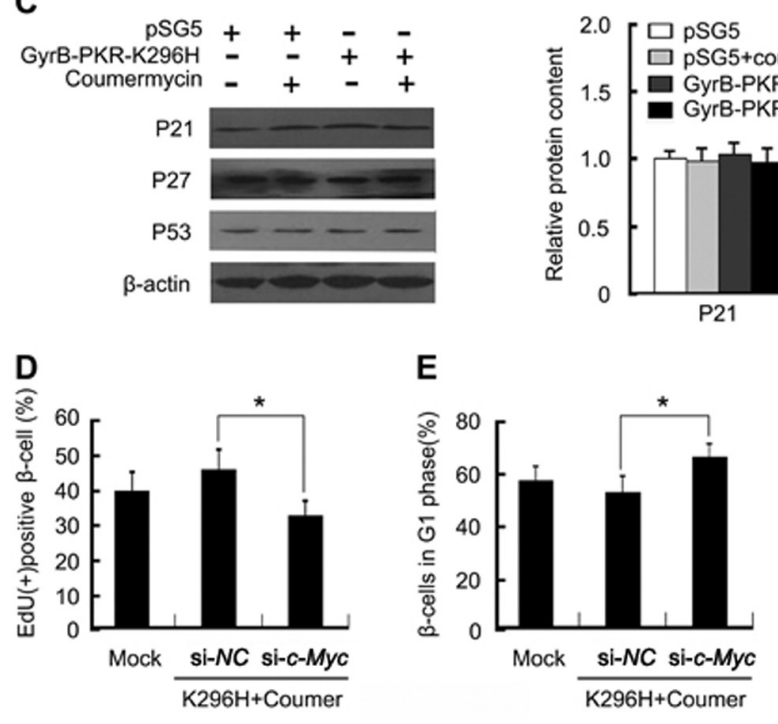

Figure 3. The PKR protein-binding function promotes cell cycle progression via upregulation of c-Myc transcription in MIN6 cells. Twenty-four hours after transfection, MIN6 cells were treated with coumermycin as indicated. (A) The mRNA levels of the indicated genes, including positive cell cycle regulators cyclin D1, D2, CDK2, CDK4 and C-Myc and negative regulators $p 18, p 27$ and p53 were determined by qRT-PCR. Cell extracts were analyzed by Western blotting with antibodies against (B) positive and (C) negative cell cycle regulators. si-c-Myc was cotransfected with GyrB-PKR-K296H into MIN6 cells, followed by treatment of coumermycin. (D) Quantification of EdU-positive $\beta$ cell and percentages of MIN6 cells at the (E) G1 phase and (F) S phase were shown. Data are means \pm SEM of three separate experiments. ${ }^{*} P<0.05$ versus control.

nuclear translocation of $\mathrm{p} 65$ is not sufficient to prove increased NF-кB transcriptional activity, therefore, a luciferase reporter assay was performed to determine the role of PKR protein binding in NF- $\mathrm{BB}$-dependent reporter gene expression. An NF-кB-dependent reporter construct, pGMNF-кB-Lu, was cotransfected into MIN6 cells with plasmid GyrB-PKR-K296H or pSG5. As shown in Figure 5C, a significant increase in NF- $\kappa$ B activity (up to five-fold) was observed under conditions of elevated PKR protein binding. These observations implied that NF- $\mathrm{\kappa B}$ activation was induced by PKR protein binding in MIN6 cells.

\section{TRAF2, but Not TRAF6, Plays a Critical Role in PKR Protein-Binding-Induced NF-KB Activation and Proliferation in MIN6 Cells}

TRAF proteins are universal adapters linking NF- $\kappa$ B activation $(19,43)$, therefore, we investigated the integration of TRAF in PKR protein-binding-induced NF- $\kappa B$ activation. In view of the binding of PKR to TRAF2 and TRAF6 in MIN6 cells (see Figure 1B), specific siRNAs for TRAF2 and TRAF6 were applied to examine their exact roles. MIN6 cells were transfected with each siRNA before cotransfection with plasmid GyrB-PKR-K296H and the NF-кBdependent reporter construct pGMNF$\kappa \mathrm{B}-\mathrm{Lu}$ and coumermycin stimuli. Compared with the control group, the luciferase activity was reduced greatly in the group subjected to TRAF2 gene silencing, however, the si-TRAF6 group was barely affected (Figure 6A, $P<$ 0.01 ). These results indicate that TRAF2 was involved in PKR protein-bindinginduced NF- $\mathrm{KB}$ activation. Consistently, the upregulation of $c-M y c$ diminished after TRAF2 gene silencing at the mRNA (Figure 6B, $P<0.01$ ) and protein levels (Figure 6C, down to 30\%). To gain deeper insight into the impact of TRAF2 on the biological function of the PKR protein-binding domain, EdU labeling and flow cytometric analysis were performed after gene silencing of TRAF2 or TRAF6. Compared with the control group, TRAF2 gene silencing obviously reduced the percentage of EdU-positive $\beta$ cells (Figure 6D, $P<$ $0.05)$, but increased the percentage of $\beta$ cells in the G1 phase (Figure 6E, $P<$ $0.05)$, along with a decreased percentage in $S$ phase (Figure $6 \mathrm{~F}, P<0.05$ ). Mean- 
A

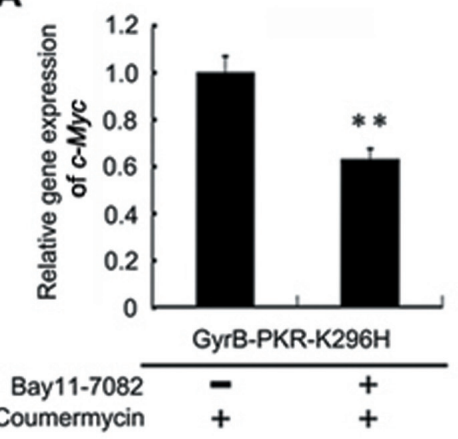

C

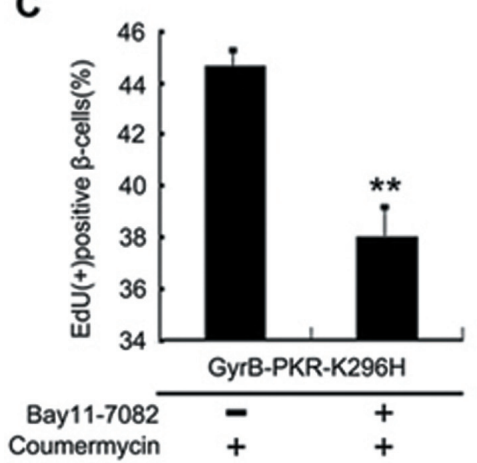

$\mathbf{E}$

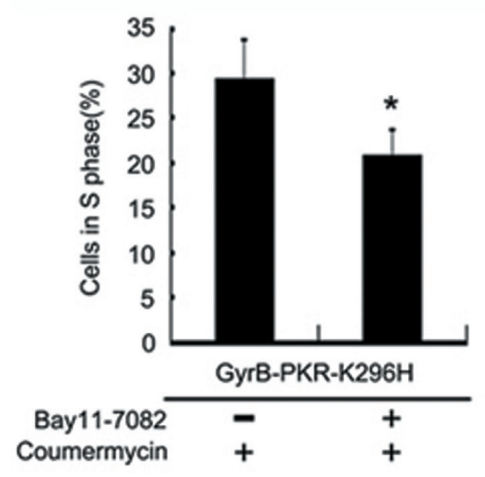

B

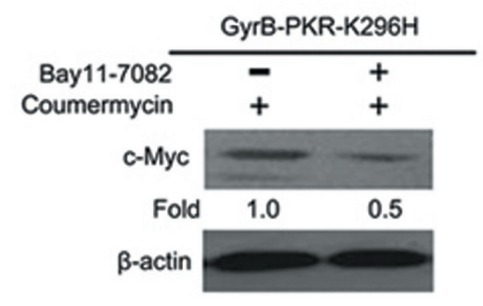

D

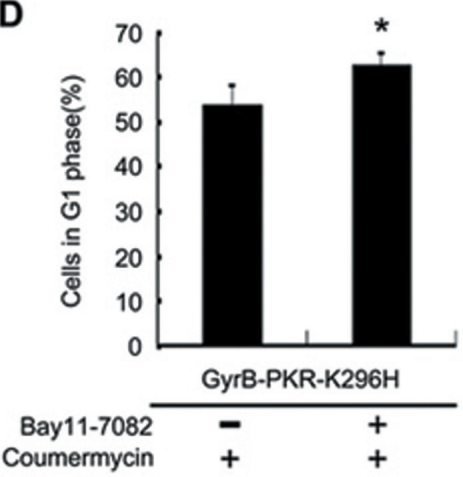

$\mathbf{F}$

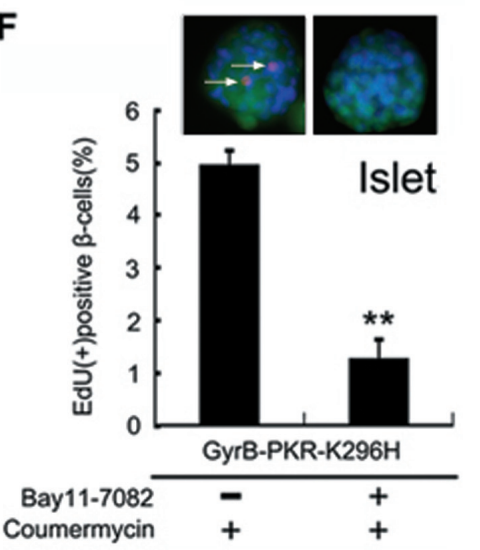

Figure 4. NF- $\mathrm{KB}$ is required for PKR protein-binding-induced $\mathrm{c}$-myc upregulation and cell proliferation in pancreatic $\beta$ cells. After transfection, MIN6 cells were pretreated with Bay $11-$ $7082(30 \mu \mathrm{mol} / \mathrm{L}, 2 \mathrm{~h})$ and subsequently treated with coumermycin for $24 \mathrm{~h}$. mRNA and protein levels of C-Myc were determined by (A) qRT-PCR and (B) Western blotting. (C) Quantification of EdU-positive $\beta$ cell and percentages of MIN6 cells at the (D) Gl phase and (E) $S$ phase were shown. (F) Isolated mouse islets were administered as panel $C$ and DNA synthesis was analyzed using EdU labeling assays. The percentage of EdU-positive $\beta$ cells in islets was quantificated (using six islets for each group). Arrows indicate the EdU-positive $\beta$ cell. $\beta$-actin was detected as an internal control. Data are means \pm SEM of three separate experiments. ${ }^{*} P<0.05$ versus control.

while, gene silencing of TRAF6 had no effect on PKR protein-binding-induced $\beta$-cell proliferation (Figures 6D-F). Taken together, the results indicated that
TRAF2, but not TRAF6, plays a critical role in PKR protein-binding-induced $\mathrm{NF}-\kappa \mathrm{B}$ activation and proliferation in MIN6 cells.
RIP1 Is Located Downstream of TRAF2 and Implicated in PKR Protein-Binding-Mediated NF-KB Activation and Proliferation in MIN6 Cells

TRAF2 can function as an E3 ubiquitin ligase in the Ubc133/Uev1A ubiquitin conjugation enzyme system, catalyzing the assembly of K63-linked polyubiquitin chains on target proteins, including TRAFs, RIP1 and IKK $\gamma / \mathrm{NEMO}$, which in turn activates the IKK complex $(21,44,45)$. As a result, RIP1 was targeted for subsequent investigation. After transfection and coumermycin treatment, MIN6 cells were collected for immunoprecipitation of RIP1 using an antibody against RIP1. Western blotting was carried out to detect ubiquitin-RIP1 using an antibody against ubiquitin. As expected, ubiquitin-RIP1 was found only in the group where PKR strongly interacted with TRAF2. To further elucidate whether the ubiquitination of RIP1 was attributed to recruitment of TRAF2 by PKR, si-TRAF2 was used to silence the TRAF2 gene in MIN6 cells. Compared with the control group, ubiquitin disappeared from the coimmunoprecipitate after gene silencing of TRAF2 (Figure 7B). Additionally, si-RIP1 interfered with NF- $\kappa B$ reporter gene expression, as observed by impaired luciferase activity (Figure 7C, left panel, $P<0.05$ ) and abolished c-Myc protein upregulation (Figure 7C, right panel, down to $40 \%$ ). As depicted in Figure 7D, PKR proteinbinding-induced $\beta$-cell proliferation of MIN6 was remarkably disturbed by si-RIP1. Based on the above data, we suggested that RIP1 acted as a downstream molecule of TRAF2 signaling and participated in PKR protein-binding-triggered signaling and MIN6 cell proliferation.

\section{PKR Protein Binding, Which Can Remit the Deleterious Effect of TNF $\alpha$ on MIN6 Cell Proliferation Also Was Evoked in Response to Glucolipitoxicity and TNF $\alpha$}

Glucolipitoxicity and proinflammatory cytokines have been identified as two critical components in the development of insulin resistance and T2DM 
A

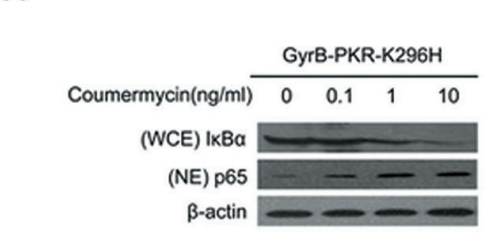

B

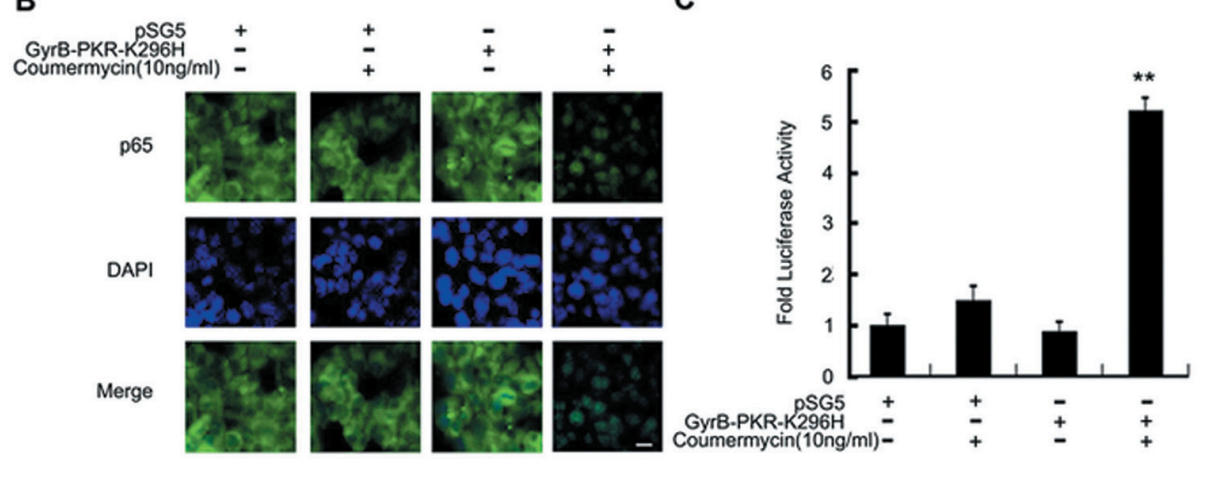

Figure 5. NF-кB was activated by the PKR protein-binding function in MIN6 cells. Twentyfour hours after transfection, MIN6 cells were treated with coumermycin as indicated.

(A) Whole cell extracts (WCE) and prepared nuclear extracts (NE) were collected and analyzed by Western blotting with antibodies against $I_{\kappa} B \alpha$ and $p 65$, respectively. (B) Administered as Figure 1B, p65 localizations in cytoplasm and nuclear of MIN6 cells were determined by IFA (scale bar $=100 \mu \mathrm{m}$ ). (C) Luciferase activity was measured and shown in fold. $\beta$-actin was detected as an internal control. Data are means \pm SEM of three separate experiments. ${ }^{*} P<0.05$ versus control.

(12,13,23,46-52). Therefore, we examined PKR protein binding in response to glucolipitoxicity and TNF $\alpha$. MIN6 cells were transfected with plasmids encoding PKR-K296R or the empty vector pSG5 and then stimulated with glucolipitoxicity (glucose $16.7 \mathrm{mmol} / \mathrm{L}$ and $0.4 \mathrm{mmol} / \mathrm{L}$ palmitate) for $6 \mathrm{~h}$. As expected, in PKRK296R-induced MIN6 cells, glucolipitoxicity induced coimmunoprecipitation of TRAF2 and TRAF6, followed by immunoprecipitation of PKR (Figure 8A). Similar results were obtained under conditions of $80 \mathrm{nmol} / \mathrm{L}$ proinflammatory cytokine TNF $\alpha$ after transfection of the PKR-K296R plasmid (see Figure 8A). Interestingly, NF-кB-dependent luciferase activity was not altered between the control and glucolipitoxicity groups, but was remarkably increased in the TNF $\alpha$ groups where PKR protein binding seemed to induce a more significant ele- vation (Figure 8B). Furthermore, c-Myc upregulation did not always correlate with NF- $\kappa$ B activation, because there was no significant increase of $c-M y c$ at the mRNA level in the group with robust NF- $\mathrm{B}$ activation mediated by PKR protein binding (Figure 8C). Still, suppressed cell viability (Figure $8 \mathrm{~F}, P<0.01$ ) and proliferation (Figure $8 \mathrm{E}, P<0.05$ ) in response to TNF $\alpha$ both were found to be relieved in PKR-K296R-induced MIN6 cells, presenting a similar result as the control groups without TNF $\alpha$ stimuli. These data indicated that PKR protein binding was indeed evoked in response to glucolipitoxicity and TNF $\alpha$, which remitted the deleterious effect of TNF $\alpha$ on MIN6 cells proliferation.

\section{DISCUSSION}

Considering that T2DM is characterized by relative insufficiency of insulin production by $\beta$ cells $(12,23,27,30,53,54)$, how to increase the $\beta$-cell mass by expending $\beta$ cells and enhancing insulin secretion are of great importance. In adult mammals, proliferation of mature $\beta$ cells plays a critical role in the maintenance of the $\beta$-cell mass (55). Hence, inducible proliferation of pancreatic $\beta$ cells in pathophysiological settings is proposed to improve T2DM. Our investigations suggested that pancreatic $\beta$-cell proliferation would be promoted by elevating the protein-binding function of PKR in the absence of its kinase catalytic activity.

PKR acts as an adaptor protein via its protein-binding domain, whose biological function may be quite different from its catalytic activity $(14,56,57)$. A pitfall in this investigation is that the $\beta$-cell line MIN6 and primary islet $\beta$ cells used were not devoid of PKR; therefore, endogenous PKR potentially would be activated upon stimulus by poly(I:C), BEPP, glucolipitoxicity or proinflammatory cytokines $(8,12,29,30,58)$ when kinase-defective mutant PKR-K296R was utilized to establish a model of elevated PKR protein-binding function. Fortunately, GyrBPKR-K296H was able to avoid such a pitfall, as demonstrated by the fact that the specific activator coumermycin $(14,22)$ had no influence on endogenous PKR activity (see Figure 1A). As depicted in Figure $1 \mathrm{~B}$, the PKR binding function was greatly upregulated after treatment by coumermycin in GyrB-PKR-K296Hinduced $\beta$-cell line, accompanied by enhanced physical interactions between PKR and TRAF2 and TRAF-6. These observations indicated prospective roles of TRAF2 and -6 in PKR protein-bindingmediated signaling pathways.

In contrast to the kinase activity of PKR, the PKR protein-binding function exhibited a proliferative role on pancreatic $\beta$ cells, indicating a kinase-free biological function of PKR. Analogous to PKR, other kinases such as RIP, IRAK, JNK1 and Tyrk2 also are able to mediate certain biological functions independent of their kinase activity when their binding domains are ready for alignment 
A
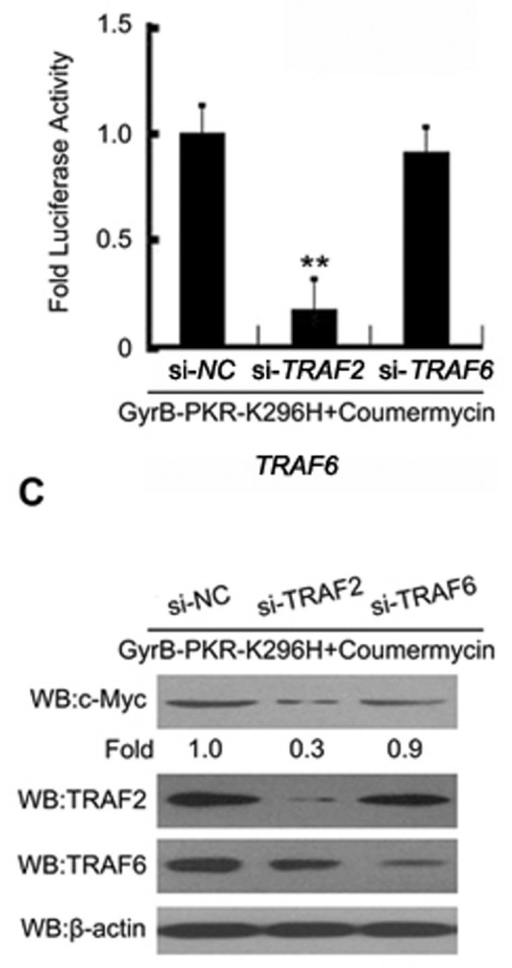

E

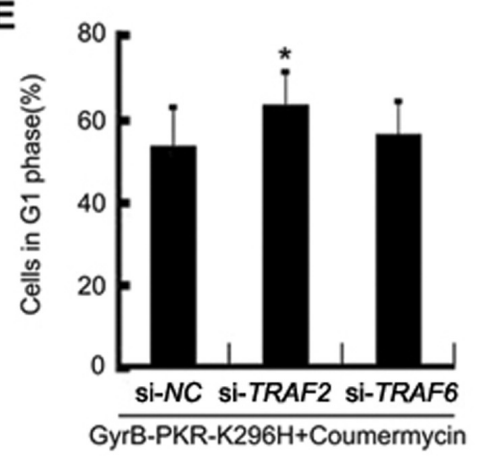

B

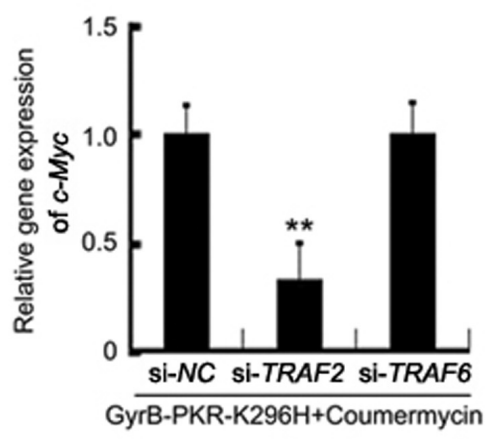

D

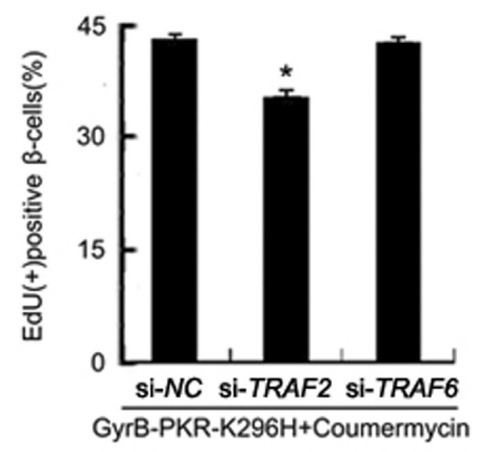

$\mathbf{F}$

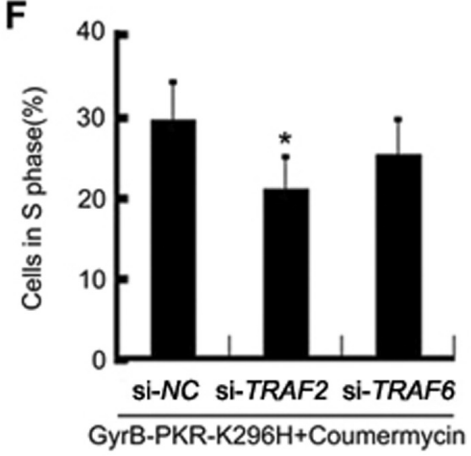

Figure 6. TRAF2 plays a critical role in PKR protein-binding-induced NF-kB activation and proliferation in MIN6 cells. MIN6 cells were transfected with si-NC, si-TRAF2 or siTRAF6 before GyrB-PKR-K296H plasmids. After $48 \mathrm{~h}$ of gene silencing, cells were treated with coumermycin as indicated. (A) Luciferase activity was measured and shown in fold. mRNA and protein levels of C-myc were determined by (B) GRT-PCR and (C) Western blotting. Antibodies against TRAF2 and TRAF6 were used to examine the protein levels after gene silencing. (D) Quantification of EdU-positive $\beta$ cell was shown. Flow cytometric assays were carried out, with percentages of MIN6 cells at the (E) Gl phase and (F) $S$ phase displayed. $\beta$-actin was detected as an internal control. Data are means \pm SEM of three separate experiments. ${ }^{*} P<0.05$ versus control.

with associated partners and trigger signals $(56,57,59,60)$. Therefore, the exact biological function of PKR is determined mainly by the predominance of related domains in certain settings. In fact, the proliferative role of PKR in cells is not infrequent, with high expression and activation levels of PKR found in various cancers (4,61-63). Further support for our data comes from the evidence that PKR participates in TNF $\alpha$-induced proliferation in mouse embryo fibroblast (MEF) (33). The impact of PKR in cellular processes of different cells or even of the same cell type, from antiproliferation to proliferation, might be separate from its kinase catalytic activity and proteinbinding function.

In the present study, the PKR proteinbinding domain-dependent proliferation seemed to correlate with reduced $\beta$ cells at G1 phase and augmented levels at $S$ phase in pancreatic $\beta$-cell line (Figure 2). This was associated with the substantial increase in the positive regulator c-Myc and was further confirmed by the antiproliferative role of $c-M y c$-siRNA (Figure 3). Generally, c-Myc hyperactivates cyclin/Cdk or antagonizes the activity of cell cycle inhibitors, such as P21 and $\mathrm{P} 27$, to drive cell cycle progression and promote cell proliferation (64). As demonstrated, modest overexpression of $\mathrm{c}-\mathrm{Myc}$ is able to drive proliferation in normal rat and human $\beta$ cells (34). In addition, $c-M y c$ mRNA was upregulated and contributed to adaptive proliferation of pancreatic islets during rat pregnancy (55). Hence, it is feasible that PKR protein-binding-induced proliferation might be closely linked with elevated levels of c-Myc proteins in pancreatic $\beta$ cells.

Correlating with previous data that c-Myc is modulated by NF- $\mathrm{\kappa B}$ transcriptional activity $(38,42)$, there was a significant boost in NF-кB-dependent luciferase activity after increased PKR protein-binding function, as well as proteolytic degradation of IкB $\alpha$ and nuclear translocation of p65 in pancreatic $\beta$-cell line (Figure 5). Most importantly, activated NF-кB in this investigation obviously promoted $\beta$-cell proliferation in pancreatic $\beta$ cells (see Figure 5). Notably, the proliferative role of NF-kB was observed previously in NIT-1 cells when stimulated with a low dosage of LPS (40). Furthermore, the PKR-facilitated prosurvival NF-kB pathway in cholangiocarcinoma cell lines is significantly 
A
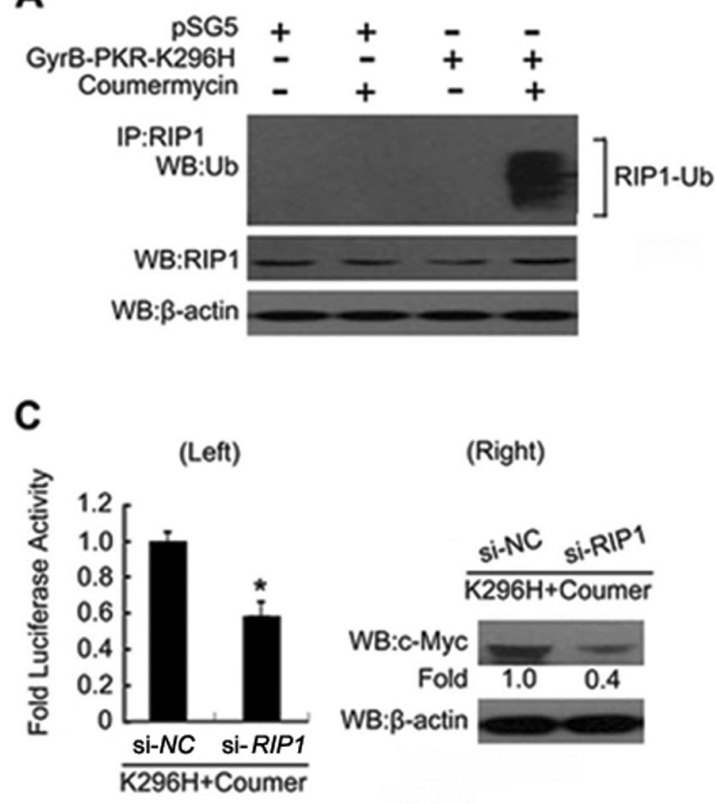

B

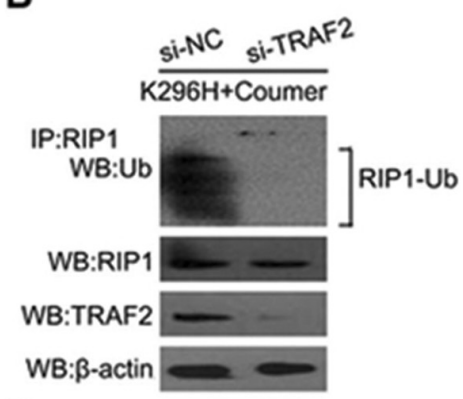

D

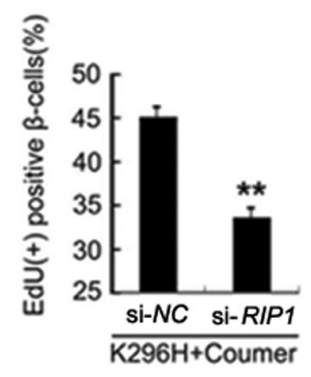

Figure 7. RIP1, located downstream of TRAF2, is implicated in PKR protein-binding-mediated NF- $\kappa B$ activation and $\beta$-cell proliferation in MIN6 cells. (A) Administered as Figure 1B, MIN6 cell extracts were collected for immunoprecipitation with antibodies against RIP1 and thoroughly washed. Immunocomplexes were analyzed by Western blotting with antibodies against ubiquitin and whole cell extracts (WCE) with anti-RIP antibody. (B) si-NC or si-TRAF2 was transfected into MIN6 cells before GyrB-PKR-K296H plasmids. Immunoprecipitation and Western blotting were performed as in panel A. (C) Twenty-four hours after transfection of siRIP1, luciferase reporter assay was conducted as in Figure 6A, and fold luciferase activity is shown (left panel); Western blot to detect c-myc protein level is described (right panel). (D) Quantification of EdU-positive $\beta$ cell was shown. $\beta$-actin was detected as an internal control. Data are means \pm SEM of three separate experiments. ${ }^{*} P<0.05$ versus control.

associated with neoplastic progression in human cancers $(61,63)$. However, previous studies also suggested that the PKR-triggered NF- $\kappa$ B pathway could cause cell death or apoptosis when eIF2 $\alpha$ was phosphorylated and activated by PKR (65). The data was in line with a previous hypothesis that PKRmediated activation of NF- $\kappa$ B has two distinctive functions decided by the presence of p-eIF2 $\alpha$ and inhibition of protein synthesis (29).

As well-characterized adaptor proteins, TRAFs have an important role in assembling active NF- $\mathrm{KB}$ signaling scaffolds in response to extracellular or intracellular stimuli $(19,43)$. To date, only TRAF2 and TRAF6 have been identified in pancreatic $\beta$ cells (66). In the immunoprecipitation experiments, these two proteins could bind with dimerized PKR (see Figure 1B), implying a possible association of TRAF2 and TRAF6 with the PKR protein-binding-dependent NF-кB pathway. Human PKR interaction with TRAFs in HeLa and 293T cells after treatment with IFN- $\alpha / \beta$ reinforces our hypothesis (14). Nevertheless, PKR protein-binding function-accelerated $\beta$-cell proliferation was reversed only by si-TRAF2, whereas si-TRAF6 produced no effect in $\beta$-cell line. We also observed abrogated NF- $\kappa \mathrm{B}$ activation and reduced c-Myc expression after gene silencing of TRAF2 (Figure 6). Thus, we concluded that TRAF2, but not TRAF6, links PKR with the proliferative pathway of NF- $\mathrm{KB}$ when recruited by PKR via the TRAF-interacting motif at the $C$ terminus (14). This conclusion was in accordance with previous evidence showing that an increase in the TRAF2 level correlated with improved cell viability of MIN6 (67), whereas TRAF6 was reported to participate in the early stages of cytokine-induced pancreatic $\beta$-cell death (68).

TRAF2-mediated NF-кB pathways contain canonical and alternative routes (69-71). However, in the alternative NF-кB pathway, downregulation of TRAF2 was shown to increase activity of the p52/RelB NF-кB complex through stabilization and activation of NF-кB-inducing kinase (NIK) (72). In this sense, TRAF2 appeared to participate in the assembly of protein complexes necessary for canonical NF- $\mathrm{KB}$ activation, where TRAF2 would form multimeric complexes and subsequently facilitate Lys63 ubiquitination of downstream molecules, including cIAP1, RIP1, TANK and TAK1 $(73,74)$. TRAF2mediated Lys63 ubiquitination of RIP1 is a prerequisite for IKK complex activation and the removal of the central in-

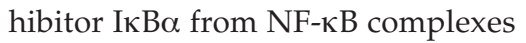
$(21,44,45,74,75)$. In the present study, RIP1 was ubiquitinated by the PKR protein-binding function, and gene silencing of TRAF2 abolished such ubiquitination in $\beta$-cell line (Figures 7A, B), confirming the involvement of RIP1 downstream of TRAF2 in PKR proteinbinding-triggered signaling. Additionally, Jackson-Bernitsas et al. clearly demonstrated that proliferation in human head and neck cancer cells was in part attributed to RIP1-associated constitutive NF- $\kappa \mathrm{B}$ activation (21). In our study, a similar role of RIP1 on proliferation in a pancreatic $\beta$-cell line was verified.

We also sought to examine whether PKR protein binding initiated and affected $\beta$-cell growth during progression of T2DM. Glucolipitoxicity and TNF $\alpha$ are closely associated with the decompensatory capacity of in vivo $\beta$-cell mass and the development of T2DM $(12,13,23,46-52)$. The catalytic activity of PKR is promoted by glucolipitoxicity and TNF $\alpha$ and implicated in $\beta$-cell pro- 


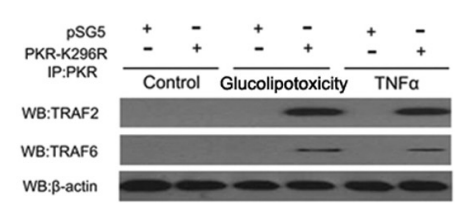

C

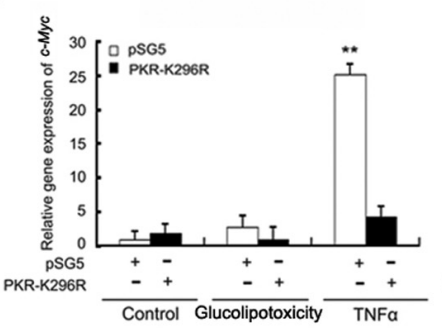

D

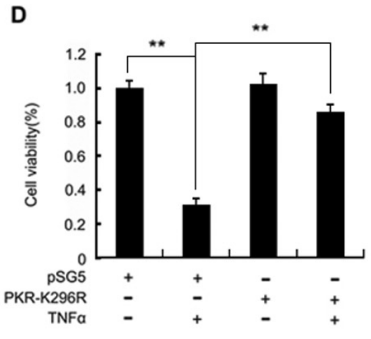

B

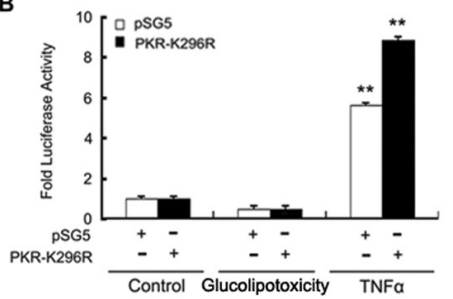

E

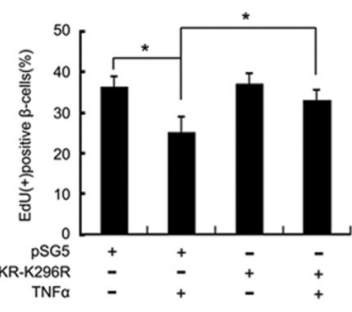

Figure 8. PKR protein binding also was evoked in response to glucolipitoxicity and TNF $\alpha$ which remitted the deleterious effect of TNF $\alpha$ on MIN6 cell proliferation. Twenty-four hours after transfection with PKR-K296R or PSG5, cells were stimulated with or without glucolipitoxicity (glucose $16.7 \mathrm{mmol} / \mathrm{L}$ and $0.05 \mathrm{mmol} / \mathrm{L}$ palmitate) or proinflammatory cytokines TNF $\alpha$ ( $80 \mathrm{ng} / \mathrm{mL}$ ) for $6 \mathrm{~h}$. (A) Immunocomplexes of PKR were analyzed by Western blotting with antibodies against TRAF2 and TRAF6. (B) Luciferase activity was measured and shown in fold. (C) mRNA and protein levels of c-myc were determined by qRT-PCR (upper panel) and Western blotting (down panel). After transfection, MIN6 cells were stimulated with TNF $\alpha$. (D) Cell viability and (E) quantification of EdU-positive $\beta$ cell of MIN6 cells were shown. $\beta$-actin was detected as an internal control. Data are means \pm SEM of three separate experiments. ${ }^{*} P<0.05$ versus control.

liferation inhibition (12). In PKR-K296Rinduced $\beta$-cell line, PKR binding with TRAF2 and - 6 was evoked in response to glucolipitoxicity and TNF $\alpha$. However, PKR protein binding could not activate NF- $\mathrm{KB}$ or $\mathrm{c}-\mathrm{Myc}$ upregulation under conditions of glucolipitoxicity. Glucolipitoxicity also can trigger endoplasmic reticulum stress, which plays an important role in insulin resistance and the decline in pancreatic $\beta$ cell mass during T2DM $(34,76,77)$. It is possible that endoplasmic reticulum stress-mediated signals would interfere with the PKR protein-binding domain-induced NF-кB pathway. In a PKR-K296R-induced $\beta$-cell line, NF- $\kappa$ B activation did not result in a remarkable increase of c-Myc mRNA level (Figures 8B, C). Since overexpressed PKR-K296R was still able to alleviate the negative impact of TNF $\alpha$ on cells viability (Figure 8D) and proliferation (Figure $8 \mathrm{E}$ ) of $\beta$-cell line, we presumed that a kinase-defective mutant may protect $\beta$ cells from TNF $\alpha$ triggered deleterious effect through downregulating c-Myc mRNA level to a reasonable extent. As a vivid example, moderate expression of c-Myc can promote cell proliferation, whereas immoderate overexpression of c-Myc can exert a negative effect on cell growth through apoptosis $(34,78,79)$. The protective effect of overexpressed mutant PKRK296R may be partially attributed to the PKR protein-binding function. Of course, its powerful competitive capacity against endogenous PKR activity elicited by TNF $\alpha$ also may play a role.

Based on our studies (12), both kinasecatalytic and protein-binding activities of PKR would be induced in the development of type 2 diabetes, despite their opposite effects. While the proliferative effort of the PKR binding function in pancreatic $\beta$ cells is highlighted, its side effect should not be overlooked. For instance, tumorigenesis might occur if the
PKR protein-binding function is elevated remarkably, leading to uncontrollable cell proliferation, and potential issues remain to be further verified.

\section{CONCLUSION}

This study shows that the PKR protein-binding function was inducible upon dimerization and could promote modest $\beta$-cell proliferation through the TRAF2/RIP1/NF-кB/c-Myc pathway when its kinase-catalytic activity was suppressed. These results indicated a therapeutic opportunity in T2DM through pharmacological maintenance of the PKR protein-binding function after suppressing kinase activity, since inducible proliferation of $\beta$ cells plays a pivotal role in the mass increase and compensatory capacity of islets for insulin resistance.

\section{ACKNOWLEDGMENTS}

We thank Charles Tom Dever for providing plasmids encoding PKR-K296R, GyrB-PKR, GyrB-PKR-K296H and pSG5. The work was supported by grants from the National Natural Science Foundation of China (no. 81170714), the Natural Science Foundation of Jiangsu Province (BK20131110) and the Priority Academic Program Development of Jiangsu Higher Education Institutions.

\section{DISCLOSURE}

The authors declare they have no competing interests as defined by Molecular Medicine, or other interests that might be perceived to influence the results and discussion reported in this paper.

\section{REFERENCES}

1. Garcia MA, et al. (2006) Impact of protein kinase PKR in cell biology: from antiviral to antiproliferative action. Microbiol. Mol. Biol. Rev. 70:1032-60.

2. Bennett RL, et al. (2012) The RAX/PACT-PKR stress response pathway promotes p 53 sumoylation and activation, leading to $G(1)$ arrest. Cell Cycle. 11:407-17.

3. Zhang S, et al. (2014) Activation of the PKR/eIF2alpha signaling cascade inhibits replication of Newcastle disease virus. Virol. J. 11:62.

4. Marchal JA, et al. (2014) The impact of PKR activation: from neurodegeneration to cancer. FASEB J. 28:1965-74. 
5. Barber GN, Jagus R, Meurs EF, Hovanessian AG, Katze MG. (1995) Molecular mechanisms responsible for malignant transformation by regulatory and catalytic domain variants of the interferoninduced enzyme RNA-dependent protein kinase. J. Biol. Chem. 270:17423-8.

6. Yim HC, Williams BR. (2014) Protein kinase R and the inflammasome. J. Interferon Cytokine Res. 34:447-54.

7. He Y, Franchi L, Nunez G. (2013) The protein kinase PKR is critical for LPS-induced iNOS production but dispensable for inflammasome activation in macrophages. Eur. J. Immunol. 43:1147-52.

8. Nakamura T, et al. (2010) Double-stranded RNAdependent protein kinase links pathogen sensing with stress and metabolic homeostasis. Cell. 140:338-48.

9. Carvalho-Filho MA, et al. (2012) Double-stranded RNA-activated protein kinase is a key modulator of insulin sensitivity in physiological conditions and in obesity in mice. Endocrinology. 153:5261-74.

10. Carvalho BM, et al. (2013) Modulation of doublestranded RNA-activated protein kinase in insulin sensitive tissues of obese humans. Obesity (Silver Spring). 21:2452-7.

11. Nakamura T, Arduini A, Baccaro B, Furuhashi M, Hotamisligil GS. (2014) Small-molecule inhibitors of PKR improve glucose homeostasis in obese diabetic mice. Diabetes. 63:526-34.

12. Chen SS, et al. (2014) Activation of double-stranded RNA-dependent protein kinase inhibits proliferation of pancreatic beta-cells. Biochem. Biophys. Res. Commun. 443:814-20.

13. Lundh M, Scully SS, Mandrup-Poulsen T, Wagner BK. (2013) Small-molecule inhibition of inflammatory beta-cell death. Diabetes Obes. Metab. 15 Suppl 3:176-84.

14. Gil J, et al. (2004) TRAF family proteins link PKR with NF-kappa B activation. Mol. Cell. Biol. 24:4502-12.

15. Oganesyan G, et al. (2006) Critical role of TRAF3 in the Toll-like receptor-dependent and -independent antiviral response. Nature. 439:208-11.

16. Sadler AJ, Williams BR. (2007) Structure and function of the protein kinase R. Curr. Top. Microbiol. Immunol. 316:253-92.

17. Li S, et al. (2006) Molecular basis for PKR activation by PACT or dsRNA. Proc. Natl. Acad. Sci. U. S. A. 103:10005-10.

18. Bradley JR, Pober JS. (2001) Tumor necrosis factor receptor-associated factors (TRAFs). Oncogene. 20:6482-91.

19. Xie P. (2013) TRAF molecules in cell signaling and in human diseases. J. Mol. Signal 8:7.

20. Ogolla PS, et al. (2013) The protein kinase double-stranded RNA-dependent (PKR) enhances protection against disease cause by a non-viral pathogen. PLoS Pathog. 9:e1003557.

21. Jackson-Bernitsas DG, et al. (2007) Evidence that TNF-TNFR1-TRADD-TRAF2-RIP-TAK1-IKK pathway mediates constitutive NF-kappaB activation and proliferation in human head and neck squamous cell carcinoma. Oncogene. 26:1385-97.
22. Ung TL, Cao C, Lu J, Ozato K, Dever TE. (2001) Heterologous dimerization domains functionally substitute for the double-stranded RNA binding domains of the kinase PKR. EMBO J. 20:3728-37.

23. Wang Y, et al. (2013) Elevated toll-like receptor 3 inhibits pancreatic beta-cell proliferation through G1 phase cell cycle arrest. Mol. Cell. Endocrinol. 377:112-22

24. Institute of Laboratory Animal Resources (U.S.), Committee on Care and Use of Laboratory Animals. (1985) Guide for the Care and Use of Laboratory Animals. Rev. 1985. Bethesda (MD): NIH. 83 pp. (NIH publication; no. 85-23).

25. Han X, Sun Y, Scott S, Bleich D. (2001) Tissue inhibitor of metalloproteinase- 1 prevents cytokinemediated dysfunction and cytotoxicity in pancreatic islets and beta-cells. Diabetes. 50:1047-55.

26. Kang HC, Bae YH. (2009) Transfection of rat pancreatic islet tissue by polymeric gene vectors. $D i-$ abetes Technol. Ther. 11:443-9.

27. Gu L, et al. (2013) Early activation of nSMase2/ceramide pathway in astrocytes is involved in ischemia-associated neuronal damage via inflammation in rat hippocampi. J. Neuroinflammation. 10:109.

28. Meng ZX, et al. (2009) Activation of liver X receptors inhibits pancreatic islet beta cell proliferation through cell cycle arrest. Diabetologia. 52:125-35.

29. Hu W, et al. (2009) Double-stranded RNAdependent protein kinase-dependent apoptosis induction by a novel small compound. J. Pharmacol. Exp. Ther. 328:866-72.

30. Hu Y, Conway TW. (1993) 2-Aminopurine inhibits the double-stranded RNA-dependent protein kinase both in vitro and in vivo. J. Interferon. Res. 13:323-8.

31. Ackermann AM, Gannon M. (2007) Molecular regulation of pancreatic beta-cell mass development, maintenance, and expansion. J. Mol. Endocrinol. 38:193-206.

32. Wang HL, et al. (2014) Mangiferin facilitates islet regeneration and beta-cell proliferation through upregulation of cell cycle and beta-cell regeneration regulators. Int. J. Mol. Sci. 15:9016-35.

33. Takada Y, et al. (2007) Genetic deletion of PKR abrogates TNF-induced activation of IkappaBalpha kinase, JNK, Akt and cell proliferation but potentiates p44/p42 MAPK and p38 MAPK activation. Oncogene. 26:1201-12.

34. Karslioglu E, et al. (2011) cMyc is a principal upstream driver of beta-cell proliferation in rat insulinoma cell lines and is an effective mediator of human beta-cell replication. Mol. Endocrinol. 25:1760-72.

35. Gao Y, et al. (2012) PERK is required in the adult pancreas and is essential for maintenance of glucose homeostasis. Mol. Cell. Biol. 32:5129-39.

36. Bourgarel-Rey V, et al. (2001) Involvement of nuclear factor kappaB in c-Myc induction by tubulin polymerization inhibitors. Mol. Pharmacol. 59:1165-70.

37. Visconti R, et al. (1997) Expression of the neoplastic phenotype by human thyroid carcinoma cell lines requires NFkappaB p65 protein expression. Oncogene. 15:1987-94.

38. Kataoka Y, Murley JS, Khodarev NN, Weichselbaum RR, Grdina DJ. (2002) Activation of the nuclear transcription factor kappaB (NFkappaB) and differential gene expression in U87 glioma cells after exposure to the cytoprotector amifostine. Int. J. Radiat. Oncol. Biol. Phys. 53:180-9.

39. Ghashghaeinia M, et al. (2011) The NFкB pathway inhibitors Bay 11-7082 and parthenolide induce programmed cell death in anucleated erythrocytes. Cell. Physiol. Biochem. 27:45-54.

40. Liu SY, et al. (2011) Lipopolysaccharide-enhanced early proliferation of insulin secreting NIT-1 cell is associated with nuclear factor-kappaB- mediated inhibition of caspase 3 cleavage. Chin. Med J. (Engl.) 124:3652-6.

41. Xu H, You M, Shi H, Hou Y. (2014) Ubiquitinmediated NFkappaB degradation pathway. Cell Mol. Immunol. 2014, Oct 27 [Epub ahead of print].

42. Schmid JA, Birbach A. (2008) IkappaB kinase beta (IKKbeta/IKK2/IKBKB) - a key molecule in signaling to the transcription factor NF-kappaB. Cytokine Growth Factor Rev. 19:157-65.

43. Takeuchi M, Rothe M, Goeddel DV. (1996) Anatomy of TRAF2. Distinct domains for nuclear factor-kappaB activation and association with tumor necrosis factor signaling proteins. J. Biol. Chem. 271:19935-42.

44. Ea CK, Deng L, Xia ZP, Pineda G, Chen ZJ. (2006) Activation of IKK by TNFalpha requires site-specific ubiquitination of RIP1 and polyubiquitin binding by NEMO. Mol. Cell. 22:245-57.

45. Habelhah H. (2010) Emerging complexity of protein ubiquitination in the NF-kappaB pathway. Genes Cancer. 1:735-47.

46. Poitout V. (2008) Glucolipotoxicity of the pancreatic beta-cell: myth or reality? Biochem. Soc. Trans. 36:901-4.

47. Somesh BP, et al. (2013) Chronic glucolipotoxic conditions in pancreatic islets impair insulin secretion due to dysregulated calcium dynamics, glucose responsiveness and mitochondrial activity. BMC Cell. Biol. 14:31.

48. Kim JW, Yoon KH. (2011) Glucolipotoxicity in pancreatic beta-Cells. Diabetes Metab. J. 35:444-50.

49. Poitout V, Robertson RP. (2008) Glucolipotoxicity: fuel excess and beta-cell dysfunction. Endocr. Rev. 29:351-66.

50. Garcia-Elorriaga G, et al. 2012. Pro-inflammatory cytokines related to severity and mortality in type 2 diabetes patients with soft tissue infection. [Article in Spanish] Rev. Med. Inst. Mex. Seguro Soc. 50:237-41.

51. Esser N, Legrand-Poels S, Piette J, Scheen AJ, Paquot N. (2014) Inflammation as a link between obesity, metabolic syndrome and type 2 diabetes. Diabetes Res. Clin. Pract. 105:141-50.

52. Kong X, et al. (2014) Glucagon-like peptide 1 stimulates insulin secretion via inhibiting RhoA/ROCK signaling and disassembling glucotoxicity-induced stress fibers. Endocrinology. 155:4676-85. 
53. Chang-Chen KJ, Mullur R, Bernal-Mizrachi E. (2008) Beta-cell failure as a complication of diabetes. Rev. Endocr. Metab. Disord. 9:329-43.

54. Hayes HL, et al. (2013) Pdx-1 activates islet alphaand beta-cell proliferation via a mechanism regulated by transient receptor potential cation channels 3 and 6 and extracellular signal-regulated kinases 1 and 2. Mol. Cell. Biol. 33:4017-29.

55. Chen G, Liu C, Xue Y, Mao X, Xu K. (2011) Molecular mechanism of pancreatic beta-cell adaptive proliferation: studies during pregnancy in rats and in vitro. Endocrine. 39:118-27.

56. Ishii T, Kwon H, Hiscott J, Mosialos G, Koromilas AE. (2001) Activation of the I kappa B alpha kinase (IKK) complex by double-stranded RNAbinding defective and catalytic inactive mutants of the interferon-inducible protein kinase PKR. Oncogene. 20:1900-12.

57. Bonnet MC, Weil R, Dam E, Hovanessian AG, Meurs EF. (2000) PKR stimulates NF-kappaB irrespective of its kinase function by interacting with the IkappaB kinase complex. Mol. Cell. Biol. 20:4532-42.

58. Green TJ, Montagnani C. (2013) Poly I:C induces a protective antiviral immune response in the $\mathrm{Pa}$ cific oyster (Crassostrea gigas) against subsequent challenge with Ostreid herpesvirus (OsHV-1 muvar). Fish Shellfish Immunol. 35:382-8.

59. Hsu H, Huang J, Shu HB, Baichwal V, Goeddel DV. (1996) TNF-dependent recruitment of the protein kinase RIP to the TNF receptor-1 signaling complex. Immunity. 4:387-96.

60. Li X, et al. (1999) Mutant cells that do not respond to interleukin-1 (IL-1) reveal a novel role for IL-1 receptor-associated kinase. Mol. Cell. Biol. 19:4643-52.

61. Kim SH, Gunnery S, Choe JK, Mathews MB. (2002) Neoplastic progression in melanoma and colon cancer is associated with increased expression and activity of the interferon-inducible protein kinase, PKR. Oncogene. 21:8741-8.

62. Kim SH, Forman AP, Mathews MB, Gunnery S. (2000) Human breast cancer cells contain elevated levels and activity of the protein kinase, PKR. Oncogene. 19:3086-94.

63. Kunkeaw N, et al. (2013) Cell death/proliferation roles for nc886, a non-coding RNA, in the protein kinase R pathway in cholangiocarcinoma. Oncogene. 32:3722-31.

64. Bretones G, Delgado MD, Leon J. (2015) Myc and cell cycle control. Biochim. Biophys. Acta. 1849:506-16.

65. Gil J, Alcami J, Esteban M. (1999) Induction of apoptosis by double-stranded-RNA-dependent protein kinase (PKR) involves the alpha subunit of eukaryotic translation initiation factor 2 and NF-kappaB. Mol. Cell. Biol. 19:4653-63.

66. Liuwantara D, et al. (2006) Nuclear factor-kappaB regulates beta-cell death: a critical role for A20 in beta-cell protection. Diabetes. 55:2491-501.

67. Zhou R, et al. (2013) Blockage of progesterone receptor effectively protects pancreatic islet beta cell viability. Steroids. 78:987-95.

68. Humphrey RK, et al. (2013) Lysine 63-linked ubiquitination modulates mixed lineage kinase-3 interaction with JIP1 scaffold protein in cytokineinduced pancreatic beta cell death. J. Biol. Chem. 288:2428-40.

69. Lin WJ, et al. (2011) Crucial role for TNF receptor-associated factor 2 (TRAF2) in regulating NFkappaB2 signaling that contributes to autoimmunity. Proc. Natl. Acad. Sci. U. S. A. 108:18354-9.

70. Hupalowska A, Pyrzynska B, Miaczynska M. (2012) APPL1 regulates basal NF-kappaB activity by stabilizing NIK. J. Cell Sci. 125:4090-102.

71. Jin HR, Jin X, Dat NT, Lee JJ. (2011) Cucurbitacin B suppresses the transactivation activity of RelA/p65. J. Cell. Biochem. 112:1643-50.

72. Doppler H, Liou GY, Storz P. (2013) Downregulation of TRAF2 mediates NIK-induced pancreatic cancer cell proliferation and tumorigenicity. PloS One. 8:e53676.

73. Sun LL, et al. (2014) Suppressive role of miR-502-5p in breast cancer via downregulation of TRAF2. Oncol. Rep. 31:2085-92.

74. Mahul-Mellier AL, et al. (2012) De-ubiquitinating protease USP2a targets RIP1 and TRAF2 to mediate cell death by TNF. Cell Death Differ. 19:891-9.

75. O'Donnell MA, Hase H, Legarda D, Ting AT. (2012) NEMO inhibits programmed necrosis in an NFkappaB-independent manner by restraining RIP1. PloS One. 7:e41238.

76. Ozcan U, et al. (2004) Endoplasmic reticulum stress links obesity, insulin action, and type 2 diabetes. Science. 306:457-61.

77. Tran K, et al. (2014) Identification of small molecules that protect pancreatic beta cells against endoplasmic reticulum stress-induced cell death. ACS Chem. Biol. 9:2796-806.

78. Pelengaris S, Khan M. (2003) The many faces of c-MYC. Arch. Biochem. Biophys. 416:129-36.

79. Pelengaris S, Khan M, Evan GI. (2002) Suppression of Myc-induced apoptosis in beta cells exposes multiple oncogenic properties of Myc and triggers carcinogenic progression. Cell. 109:321-34.

Cite this article as: Gao L, et al. (2015) Protein-binding function of RNA-dependent protein kinase promotes proliferation through TRAF2/RIP1/NF-кB/c-Myc pathway in pancreatic $\beta$ cells. Mol. Med. 21:154-66. 